\title{
Formulasi dan Uji Kecerahan Ekstrak Krim Lulur Daun Kelor (Moringa oleifera) Sebagai Pemutih Kulit Pada Tikus Putih (Rattus norvegicus)
}

\author{
Dzun Haryadi Ittiqo ${ }^{a}{ }^{\star}{ }^{*}$, Ardiansyah $^{a, 2}$, Yuli Fitriana ${ }^{a, 3}$ \\ aProgram Studi Farmasi, FIK Universitas Muhammadiyah Mataram, Mataram, NTB, Indonesia, 83120 \\ 11dzun.haryadi@gmail.com; 3yulifitriana.82@gmail.com \\ ${ }^{*}$ korespondensi penulis
}

INFO ARTIKEL

Diterima :

I9-0I-202I

Disetujui :

23-0I-202I

\section{Kata kunci:}

Kosmetik;

Lulur;

Krim;

Daun Kelor;

Pencerah.

\section{ABSTRAK}

Kosmetik pada umumnya mengandung senyawa kimia. Lulur banyak digunakan untuk mencerahkan kulit. Untuk menjaga keamanan diperlukan senyawa aktif yang aman. Antioksidan sering dimanfaatkan pada kosmetika. Daun kelor mengandung senyawa antioksidan. Tujuan dari penelitian ini adalah untuk mengetahui mutu fisik lulur krim ekstrak daun kelor, mengetahui pada konsentrasi berapa dari ekstrak daun kelor sebagai lulur krim dapat mencerahkan kulit. Metode penelitian ini bersifat true eksperimental dengan pendekatan post test only control grup. Menggunakan hewan uji tikus sebanyak 4 ekor yang dibagi menjadi empat kelompok, kelompok I kontrol negative( basis lulur krim), kelompok 2 konsentrasi ekstrak 10\%, kelompok 3 konsentrasi ekstrak 20\% dan kelompok 4 konsentrasi ekstrak 30\%. Perlakuan hewan uji dilakukan selama satu minggu, dengan pengukuran skala warna kulit menggunakan skin tone. Analisis data menggunakan one way annova. Hasil Uji sifat fisik memberikan mutu yang baik dengan rata-rata uji $\mathrm{pH}$ sediaan 6.7, daya lekat 39 detik dan daya sebar $6,608 \mathrm{~cm}^{2}$. Porsentase kecerahan menunjukkan bahwa kelompok kontrol negativ tidak ada perubahan, kelompok 2 konstrasi I0\% (6,00 hari $\pm 0,82)$, kelompok konsentrasi 20\% (5,00 hari $\pm 0,82)$ dan konsentrasi 30\% (3.50 hari士0,58). Dapat disimpulkan bahwa krim lulur esktrak daun kelor dengan kosntrasi 30\% paling efektif mencerahkan kulit.

\section{ABSTRACT}

Cosmetics generally contain chemical compounds. Lulur is widely used to brighten the skin. To maintain safety, a safe active compound is needed. Antioxidants are often used in cosmetics. Moringa leaves contain antioxidant compounds. The purpose of this study was to determine the physical quality of the Moringa leaf extract cream scrub, knowing at what concentration of Moringa leaf extract as a cream scrub can brighten the skin. This research method is true experimental with a post test only control group approach. Using 4 rats, divided into four groups, group I was negative control (cream scrub base), group 2 extract concentration was $10 \%$, group 3 extract concentration was $20 \%$ and group 4 extract concentration was $30 \%$. The treatment of the tested animals was carried out for one week, by measuring the skin color scale using the skin tone. Data analysis used one way annova. The physical properties test results gave good quality with an average $\mathrm{pH}$ test of 6.7 , adhesion 39 seconds and spreadability $6.608 \mathrm{~cm} 2$. The percentage of brightness shows that the negative control group has no change, group 2 is $10 \%$ ( 6.00 days \pm 0.82 ), the concentration group is $20 \%$ (5.00 days \pm 0.82$)$ and the concentration is $30 \%$ ( 3.50 days $\pm 0,58$ ). It can be concluded that Moringa leaf extract cream with a concentration of $30 \%$ is the most effective in lightening the skin.

This is an open access article under the CC-BY-SA license. 


\section{Pendahuluan}

Kosmetik saat ini mengandung sejumlah besar bahan kimia dan sebagian besar tidak mengikuti peraturan administrasi yang diatur pada makanan dan obat obatan, sebagian kecil telah dievaluasi potensi merugikan bagi kesehatan(Erika Chow \& Mahalingaiah, 2017). saat ini orang lebih mengarah pada pengobatan alami, untuk kosmetik herbal kosmetik lebih alami karena dibuat dari herba maupun ekstrak tanaman. Kandungan herbal tidak memiliki efek samping pada tubuh manusia tetapi memperkaya tubuh dengan nutrisi dan mineral yang bermanfaat(Mishra et al., 2014). Oleh karena itu penggunaan bahan baku alam akan menjadi pilihan utama dimasa depan, karena khasiat dan faktor keamanannya.

Moringa oleifera adalah salah satu sayuran dari keluarga Moringaceae. Tanaman kelor tanpa disadari banyak digunakan dalam pengobatan. umumnya digunakan dalam berbagai produk perawatan kesehatan termasuk pelembab tubuh dan rambut dan diklaim sebagai tanaman yang paling kaya gizi. Berdasarkan uji fitokimia, daun kelor (Moringa oleifera) mengandung tannin, steroid dan triterpenoid, flavonoid, saponin, antarquinon, dan alkaloid, dimana semuanya merupakan antioksidan(Faizal et al., 2014) Menurut hasil penelitian, dalam daun kelor segar memiliki kekuatan antioksidan 7 kali lebih banyak dibandingkan vitamin C (Haldar \& Sharda Kosankar, 2017).

Lulur badan (body scrub) Lulur adalah sediaan cair maupun setengah padat yang berupa emulsi untuk mengangkat kotoran sel kulit mati yang tidak terangkat sempurna oleh sabun dan memberikan kelembaban serta mengembalikan kelembutan kulit, seperti kelenjar rambut dan keringat(Sari Neng Hari, 2015). Selain itu lulur dapat meningkatkan sirkulasi darah dalam tubuh dan mensuplai vitamin untuk kulit serta sebagai antioksidan(Triastuti D et al., 2018)

Krim merupakan salah satu kosmetik yang paling banyak digunakan sehingga harus memenuhi kriteria yang ditentukan diantaranya stabil, lunak, mudah dipakai, dan terdistribusi secara merata. Salah satu aktivitas paling penting dalam suatu formulasi yaitu evaluasi kestabilan fisik suatu bentuk sediaan obat. Sediaan krim yang tidak stabil akan menimbulkan terjadinya kriming, pemisahan fase, serta terjadinya inversi fase(Anief, I999).

Kualitas suatu produk ditentukan oleh formula yang digunakan. Sehingga pentingnya formulasi untuk mendapatkan kualitas produk yang dihasilkan baik dengan memperhatikan konsentrasi serta karakteristik bahan yang digunakan dan dapat dikombinasikan dengan baik dan benar. Formulasi pada sediaan krim akan mempengaruhi jumlah dan kecepatan zat aktif yang akan diabsorbsi. Zat aktif dalam sediaan krim masuk kedalam basis yang akan membawa obat untuk kontak dengan permukaan kulit. Bahan pembawa yang digunakan untuk sediaan topikal akan memiliki pengaruh besar terhadap absorbsi obat dan memiliki efek yang menguntungkan jika dipilih secara tepat(FX Grace, C Darsika, KV Sowmya, K Suganya, 2015)

Pada penelitian ini, ekstrak daun kelor diformulasikan dalam bentuk sediaan krim dengan menggunakan berbagai variasi perbandingan bahan pembawa atau basis. Berdasarkan paparan diatas, penelitian ini dimaksudkan untuk menghasilkan formulasi dan uji sifat fisik serta uji kecerahan dari lulur krim daun kelor untuk perawatan tubuh pada hewan uji tikus.

\section{Metode}

\section{Alat dan Bahan}

Alat - alat yang digunakan dalam penelitian ini adalah pisau, nampan, timbangan digital, cawan porselin, batang pengaduk, mortir, stamper, sudip, beker gelas, gelas ukur, water bath, pot/ tempat kosmetik, alat daya lekat, objek gelas, lampu UV A, $\mathrm{pH}$ meter dan skin tone (produk fair hand lovely).

Bahan yang digunakan dalam penelitian ini adalah ekstrak daun kelor, aquadest, cetyl alcohol, propilen glikol, trietanolamin, asam stearate, tablet INH 300 $\mathrm{mg}$.

Hewan uji yang digunakan pada kelompok ini adalah tikus putih (Rattus Norvegicus) galur wistar baik jantan maupun betina.

\section{Jalannya Penelitian}

Pembuatan Ekstrak Daun Kelor

Serbuk daun kelor ditimbang seberat 5I5 gram, kemudian dipindahkan ke dalam botol gelap yang ditambahkan $5 \mathrm{~L}$ etanol 70\%,selanjutnya diaduk dan ditutup. Setelah itu didiamkan selama I x 24 jam. Dalam proses perendaman dilakukan penggojogan minimal 3x. Hasil dari proses perendaman disaring kemudian selanjutnya di pekatkan di atas waterbath dengan suhu $50^{\circ} \mathrm{C}$ sehingga diperoleh ekstrak kental(Widya et al., 2013).

Uji kwalitatif kandungan senyawa

Identifikasi Alkaloid: I gram ekstrak ditambah dengan sedikit larutan $\mathrm{HCl} 2 \mathrm{~N}$, dipanaskan kemudian ditambahkan larutan Mayer terbentuk endapan menggumpal berwarna putih atau kuning dan dengan Dragendrof terbentuk endapan berwarna coklat sampai hitam, maka ada kemungkinan terdapat alkaloid.(Widya et al., 2013).Identifikasi Saponin : $10 \mathrm{~mL}$ air panas dalam 
tabung reaksi didinginkan kemudian ditambahkan 0,5 gram ekstrak dan

dikocok kuat-kuat selama IO detik. Uji positif ditunjukkan dengan terbentuknya buih yang stabil selama tidak kurang dari $\mathrm{I} 0$ menit setinggi $\mathrm{I}-\mathrm{IO} \mathrm{cm}$. Pada penambahan $\mathrm{HCl} 2 \mathrm{~N}$ buih tidak hilang(Widya et al., 2013)

Pembuatan Lulur

Fase minyak (cetyl alkohol dan asam stearat) dilebur bersamaan diatas penangas air pada suhu 70 derajat (massa I), propilen glikol, gliserin, TEA dilarutkan dalam air bersuhu 80 derajat diaduk hingga homogen (massa 2) kemudian massa I dan massa 2 dicampur sambil aduk perlahan hingga membentuk basis lulur body scrub (massa 3). Kemudian ditambahkan ekstrak daun kelor lalu aduk ad homogen. Dibiarkan dingin dan dimasukkan kedalam wadah beri etiket(Lestari, 2017).

Uji Sifat Fisik

Evaluasi fisik sediaan krim yang dilakukan meliputi pengamatan pengukuran $\mathrm{pH}$, uji daya lekat, uji daya sebar, dan uji stabilitas krim.

a. Pengamatan Organoleptis

Pemeriksaan organeoleptik meliputi warna, konsistensi dan bau sediaan lulur $\operatorname{krim}(\mathrm{M}$ et al., 2016).

b. Pengukuran $\mathrm{pH}$

Sebanyak I gram sediaan diencerkan dengan air suling hingga $\mathrm{IO} \mathrm{mL}$. Diambil sediaan dan ditempatkan pada tempat sampel $\mathrm{pH}$ meter, kemudian ditunggu hingga indikator $\mathrm{pH}$ meter stabil dan menunjukkan nilai $\mathrm{pH}$ yang konstan(Engelina NG, 2013)

c. Uji daya lekat

Sebanyak 0,3 gram krim dioleskan tipis di atas gelas objek. Gelas objek yang lain diletakkan di atas krim tersebut, kemudian ditekan dengan beban I kg selama 5 menit. Dipasang gelas objek pada alat tes, kemudian dilepaskan beban seberat 80 gram dan di catat waktunya hingga kedua objek ini terlepas(Engelina NG, 2013)

d. Uji daya sebar

Sebanyak0,5 gram krim hasil formulasi ditimbang dan diletakkan dengan hati-hati di atas kertas grafik yang dilapisi kaca arloji, diberi beban 150 gram dan dibiarkan selama 60 detik, dan dihitung pertambahan luasnya (Engelina NG, 2013)

Uji Efektifitas Variasi Konsentrasi Lulur Daun Kelor Hewan uji di bagi menjadi empat kelompok yang masing-masing kelompok terdiri dari I ekor tikus. Rambut punggung tikus dicukur dengan luas $4 \times 3 \mathrm{~cm}$. Tikus diberikan isoniazid secara oral dengan dosis $5,4 \mathrm{mg} / \mathrm{ml}$ dan dibiarkan $\pm \mathrm{I}$ jam. Isoniazid digunakan agar kulit tikus lebih sensitif terhadap sinar UV. Tikus kemudian dipaparkan sinar UV-A sampai tingkat warna kulit nomor 4 selama 20 menit yang di ukur dengan skin tone. Kelompok I (basis), Kelompok 2 dioleskan dengan konsentrasi formula I0\%, kelompok 3 dengan konsentrasi 20\% dan kelompok 4 dengan konsentrasi 30\%. Jumlah yang dioleskan sebanyak 0.I g dengan frekuensi dua kali sehari pada kulit punggung tikus. Analisi dilakukan terhadap peningkatan warna atau kecerahan kulit menggunakan skin tone(Engelina NG, 2013).

\section{Hasil Dan Pembahasan}

Ekstraksi dilakukan dengan metode maserasi, sebanyak 515 g serbuk daun kelor di rendam dengan etanol 70\% menghasilkan I2,5 g ekstrak dengan rendemen 2,43\%. Maserasi dipilih karena dapat mengekstrak senyawa dengan baik dan dapat mencegah dekomposisi senyawa yang labil terhadap pemanasan.

Sebelum melakukkan penelitian dilakukan uji pendahuluan atau uji senyawa yang terkandung dalam ekstrak, meliputi uji alkaloid dan saponin.Hasil uji dapat dilihat pada tabel I

Tabel I. Hasil Uji Pendahuluan Senyawa

Metabolitme Sekunder ekstrak daun kelor

\begin{tabular}{l|l}
\hline Senyawa & Hasil \\
\hline Alkaloid & + \\
Saponin & +
\end{tabular}

. Keterangan: $(+)$ positif: mengandung golongan senyawa; (-) negatif: tidak mengandung golongan senyawa.

Pembuatan sediaan lulur dalam krim dengan tipe minyak dalam air (M/A) karena dapat memberikan efek dingin pada kulit, mudah dicuci, tidak menimbulkan bekas setelah pemakaian, tidak berminyak dan memiliki kemampuan menyebar yang baik.

Masing-masing formula dibuat dengan bobot 25 gram dengan porsentase komponen penyusun lulur krim mengacu pada hand book of pharmaceutical eksiien, seperti terlihat pada tabel 2 .

Tablel 2. Formmula lulur krim ekstarak daun kelor (Moringa oleifera)

\begin{tabular}{lcccl}
\hline \multirow{2}{*}{ Bahan } & \multicolumn{3}{c}{ Konsentrasi $(\%$} & \\
& FI & F2 & F3 & \\
\hline Ekstrak & I0 & 20 & 30 & Zat aktif \\
Cetyl & 2 & 3 & 5 & Pengemulsi \\
Alkohol & & & & \\
\hline
\end{tabular}


Tablel 2. Formmula lulur krim ekstarak daun kelor (Moringa oleifera)

\begin{tabular}{|c|c|c|c|c|c|}
\hline \multirow{2}{*}{ Bahan } & \multicolumn{3}{|c|}{$\begin{array}{c}\text { Konsentrasi }(\% \\
\mathrm{b} / \mathrm{b})\end{array}$} & \multirow{2}{*}{\multicolumn{2}{|c|}{ kegunaan }} \\
\hline & FI & F2 & $\mathrm{F} 3$ & & \\
\hline $\begin{array}{l}\text { Profilen } \\
\text { Glikol }\end{array}$ & I & 5 & I5 & I5 & Humektan \\
\hline $\begin{array}{l}\text { Trietanolami } \\
\mathrm{n}\end{array}$ & 2 & & 3 & 5 & Emulgator \\
\hline Asam Stearat & I & 0 & 10 & I0 & Emulgator \\
\hline Aquadest & $\begin{array}{l}\mathrm{I} \\
0\end{array}$ & & $\begin{array}{l}\text { I0 } \\
0\end{array}$ & $\begin{array}{l}\text { I0 } \\
0\end{array}$ & pembawa \\
\hline
\end{tabular}

Teknik pencampuran komponen formula krim ekstrak daun kelor dilakukan dalam mortir dan stamfer hangat. Hal ini merupakan salah satu cara untuk memperlambat penurunan suhu massa, sekaligus mencegah terjadinya massa membeku/memadat.

Uji organoleptis digunakan untuk memeriksa tampilan fisik dari sediaan lulur menggunakan panca indra. Pemeriksaan meliputi, bentuk/konsistensi, warna dan bau, hasil uji seperti pada tabel 3.

Tabel 3. Hasil uji organoleptis

\begin{tabular}{|c|c|c|c|}
\hline $\begin{array}{l}\text { Konsentrasi } \\
\text { Lulur Krim } \\
\end{array}$ & konsistensi & Warna & Bau \\
\hline $\begin{array}{l}\text { Kontrol } \\
\text { (basis) }\end{array}$ & Semi padat & putih & $\begin{array}{l}\text { Bau } \\
\text { khas } \\
\text { kelor }\end{array}$ \\
\hline $\begin{array}{l}\text { Konsentrasi } \\
10 \%\end{array}$ & Semi padat & $\begin{array}{l}\text { Hijau } \\
\text { kecoklatan }\end{array}$ & $\begin{array}{l}\text { Bau } \\
\text { khas } \\
\text { kelor }\end{array}$ \\
\hline $\begin{array}{l}\text { Konsentrasi } \\
20 \%\end{array}$ & Semi padat & Coklat & $\begin{array}{l}\text { Bau } \\
\text { khas } \\
\text { kelor }\end{array}$ \\
\hline $\begin{array}{l}\text { Konsentrasi } \\
30 \%\end{array}$ & Semi padat & $\begin{array}{l}\text { Coklat } \\
\text { pekat }\end{array}$ & $\begin{array}{l}\text { Bau } \\
\text { khas } \\
\text { kelor }\end{array}$ \\
\hline
\end{tabular}

Uji pH merupakan faktor yang penting dalam krim karena krim di aplikasikan untuk penggunaan luar yang diperuntukkan untuk kulit,krim yang terlalu asam akan mengakibatkan iritasi kulit sedangkan krim yang terlalu basa akan menyebabkan kulit kering. Menurut Standar Nasional Indonesia(Dzun Haryadi Ittiqo \& Mila Yuni Anderiani, 2017). PH krim adalah 4-8. pH krim lulur ekstrak daun kelor memenuhi standar kualitas $\mathrm{pH}$ krim dengan rata-rata $\mathrm{pH}$ 6,7 seperti yang terlihat pada tabel 4 .
Tabel 4. Hasil uji pada pemeriksaan $\mathrm{pH}$

\begin{tabular}{llc}
\hline No & Konsentrasi Lulur Krim & $\begin{array}{c}\text { Hasil Uji } \\
\text { PH }\end{array}$ \\
\hline I & Kontrol(basis) & 6,4 \\
2 & Konsentrasi 10\% & $7, \mathrm{I}$ \\
3 & Konsentrasi 20\% & 6,5 \\
4 & Konsentrasi 30\% & 6,8 \\
\hline
\end{tabular}

Hal ini sesuai dengan penelitian krim lainnya penggunaan TEA yang mengandung gugus basa menyebabkan $\mathrm{pH}$ sediaan menjadi tinggi dan dapat menetralkan asam stearat(Engelina NG, 2013).

Sediaan lulur krim yang dapat dikatakan memenuhi sifat mekanik yang optimal, jika sediaan mudah dikeluarkan dari wadah dan memiliki daya sebar yang baik pada kulit ketika sediaan diaplikasikan sehingga dapat memberikan kenyamanan untuk konsumen(Garg et al., 2002). Daya sebar lulur krim diperlihatkan oleh diameter dan luas sebar terhadap beban yang ditambahkan. Persyaratan daya sebar untuk sediaan topikal adalah 5-7 $\mathrm{cm}^{2}$ (Lestari, 2017). Hasil uji daya sebar dapat dilihat pada tabel 5. Data menunjukkan formula lulur krim dengan konstrasi 10\%, 20\% dan 30\% memenuhi pesrsyaratan uji daya sebar dengan rentang uji daya sebar diantra $5-7 \mathrm{~cm}^{2}$.

Pengujian daya lekat bertujuan untuk mengetahui waktu yang dibutuhkan krim tersebut untuk melekat pada kulit. Daya lekat yang baik memungkinkan obat tidak mudah terlepas dan semakin lama melekat atau kontak dengan kulit, sehingga dapat menghasilkan efek yang lebih panjang dan sesuai yang diharapkan. Dari hasil uji daya lekat terlihat semakin tinggi konsentrasi lulur menghasilkan waktu lekat yang panjang dengan konsentrasi 30\% paling tinggi yaitu I(satu) menit 58 (Limapuluh Delapan) detik Persyaratan daya lekat yang baik untuk sediaan topikal adalah $\geq 4$ detik(Mukhlishah et al., 2016). Adapun hasil daya lekat krim lulur dapat dikatakan memenuhi persyaratan, dapat dilihat pada tabel 5 .

Tabel 5. Hasil uji daya lekat dan uji daya sebar

\begin{tabular}{llll}
\hline No & $\begin{array}{l}\text { Konsentrasi } \\
\text { Lulur Krim }\end{array}$ & $\begin{array}{l}\text { Hasil } \\
\text { uji daya } \\
\text { sebar } \\
\left(\mathrm{cm}^{2}\right)\end{array}$ & $\begin{array}{l}\text { Hasil } \\
\text { uji daya } \\
\text { lekat }\end{array}$ \\
\hline I & $\begin{array}{l}\text { Kontrol } \\
\text { (basis) }\end{array}$ & 8,23 & 3 detik \\
2 & $\begin{array}{l}\text { Konsentrasi } \\
\text { I0\% }\end{array}$ & 5,7 & 5 detik \\
3 & $\begin{array}{l}\text { Konsentrasi } \\
20 \%\end{array}$ & 6,1 & 30 detik \\
4 & $\begin{array}{l}\text { Konsentrasi } \\
30 \%\end{array}$ & 6,4 & $\begin{array}{l}\text { I menit } \\
58 \text { detik }\end{array}$ \\
\hline
\end{tabular}


Hasil uji pencerah diukur mengukur menggunakan skin tone, yang dimana sebelumnya hewan uji di adaptasikan terlebih dahulu selama 3 hari untuk menghindari stres. Sebelum diolesi lulur krim daun kelor punggung tikus di cukur kemudian tikus di suntik oral dengan suspensi isoniazid. Kulit tikus di paparkan sinar UV-a selama 20 menit sampai kulit tikus berubah menjadi kecoklatan. setelah dipaparkan lulur ekstrak kelor kulit tampak lebin cerah dibanding sebelumnya karena tumbuh sel kulit baru yang mengandung pigmen melanin lebih rendah (Engelina NG, 2013). Data menunjukkan semakin tinggi konsentrasi ekstrak lulur krim yang di oleskan semakin cepat terjadi pencerahan kulit tikus, seperti terlihat pada tabel 6 .

Tabel 6. Hasil Uji Efektivitas Variasi Konsentrasi ekstrak krim lulur daun kelor

\begin{tabular}{|c|c|c|c|}
\hline No & $\begin{array}{l}\text { Konsentrasi } \\
\text { Lulur Krim }\end{array}$ & Tikus & \begin{tabular}{l}
\multicolumn{2}{l}{ Perubahan } \\
warna kulit \\
tikus dari \\
skala 4 ke 2 \\
selama 7 \\
hari
\end{tabular} \\
\hline I & $\begin{array}{l}\text { Kontrol } \\
\text { (basis) }\end{array}$ & $\begin{array}{l}\text { replikasi I } \\
\text { replikasi } 2 \\
\text { replikasi } 3 \\
\text { replikasi } 4\end{array}$ & $\begin{array}{l}\text { Tidak ada } \\
\text { perubahan } \\
\text { Tidak ada } \\
\text { perubahan } \\
\text { Tidak ada } \\
\text { perubahan } \\
\text { Tidak ada } \\
\text { perubahan }\end{array}$ \\
\hline 2 & $\begin{array}{l}\text { Konsentrasi } \\
10 \%\end{array}$ & $\begin{array}{l}\text { replikasi I } \\
\text { replikasi } 2 \\
\text { replikasi } 3 \\
\text { replikasi } 4\end{array}$ & $\begin{array}{l}7 \\
6 \\
5 \\
6\end{array}$ \\
\hline 3 & $\begin{array}{l}\text { Konsentrasi } \\
20 \%\end{array}$ & $\begin{array}{l}\text { replikasi I } \\
\text { replikasi } 2 \\
\text { replikasi } 3 \\
\text { replikasi } 4\end{array}$ & $\begin{array}{l}6 \\
4 \\
5 \\
4\end{array}$ \\
\hline 4 & $\begin{array}{l}\text { Konsentrasi } \\
30 \%\end{array}$ & $\begin{array}{l}\text { replikasi I } \\
\text { replikasi } 2 \\
\text { replikasi } 3 \\
\text { replikasi } 4\end{array}$ & $\begin{array}{l}4 \\
4 \\
4 \\
3\end{array}$ \\
\hline
\end{tabular}

Berdasarkan tabel 6, krim lulur ekstrak daun kelor konstrasi 30\% adalah konsentrasi yang paling efektif dalam memberikan efek pencerah pada kulit tikus dengan rata-rata waktu 3,5 hari, telah bisa mengubah skala warna dari skala 4 ke skala 2 , sedangkan pada kontrol normal selama satu minggu belum bisa memberi perubahan warna. Untuk mengetahui perbedaan antar kelompok data selanjutnya diuji statistik dengan metode anova maka didapatkan hasil seperti pada tabel 7 .
Tabel 7. Uji statistik kecerahan

\begin{tabular}{llll}
\hline No & $\begin{array}{l}\text { Konsentrasi } \\
\text { Lulur Krim }\end{array}$ & Mean \pm SD & \\
\hline I & Kontrol & $\begin{array}{l}\text { Tidak } \\
\text { perubahan }^{\mathrm{c}}\end{array}$ & ada \\
2 & Konsentrasi & $6,00 \pm 0,82^{\mathrm{b}}$ & \\
& $\begin{array}{l}\text { I0\% } \\
3\end{array}$ & $\begin{array}{l}\text { Konsentrasi } \\
20 \%\end{array}$ & $5,00 \pm 0,82^{\mathrm{b}}$ \\
& $\begin{array}{l}\text { Konsentrasi } \\
4\end{array}$ & $3,50 \pm 0,58^{\mathrm{a}}$ & \\
& $30 \%$ & & \\
\hline
\end{tabular}

Ket : Tanda yang sama (b) menunjukkan tidak ada perbedaan yang signifikan

Berdasarkan tabel 7 dapat disimpulkan bahwa ada perbedaan yang signifikan antara kelompok kontrol normal dengan kelompok konsentrasi $10 \%$, $20 \%$ dan 30\% karena nilai signifikansinya $(\mathrm{p}<0.05)$. tapi, antara konsentrasi 10\% dengan 20\% tidak ada perbedaan yang signifikan karena nilai $(\mathrm{p}>0.05)$ sedangkan terdapat perbedaan yang signifikan antara konsentrasi 10\%, 20\% dengan konsentrasi 30\% karena nilai signifikansinya $(\mathrm{p}<0.05)$. berdasarkan uji duncan bahwa konsentrasi $30 \%$ adalah konsentrasi krim lulur daun kelor yang paling efektif dalam memberikan perubahan skala warna dari skala 4 ke 2 dalam waktu yang cepat yaitu dengan rata-rata 3,5 hari. Daun kelor memiliki efek pencerah karena mengandung senyawa alkaloid dan saponin termasuk flavonoid yang dapat berfungsi sebagai anti oksidan(Widya et al., 2013)

\section{Simpulan}

Berdasarkan hasil penelitian dapat disimpulkan bahwa ; I) Mutu fisik lulur krim ekstrak tanaman Daun Kelor (moringa oleifera) memenuhi persyaratan mutu dengan uji ph rata-rata 6,7 , daya lekat 39 detik dan daya sebar $6,61 \mathrm{~cm}^{2}, 2$ ) Porsentase kecerahan menunjukkan bahwa kelompok kontrol negativ tidak ada perubahan, kelompok 2 konstrasi I0\% (6,00 hari $\pm 0,82$ ), kelompok konsentrasi 20\% $(5,00$ hari $\pm 0,82)$ dan konsentrasi 30\% (3.50 hari士0,58), 3) Lulur krim ekstrak Daun Kelor (moringa oleifera)dengan konsentrasi 30\% merupakan konsentrasi yang paling baik dan paling efektif untuk mencerahkan kulit.

\section{Daftar Pustaka}

Anief, M. (1999). Ilmu Meracik Obat. Gadjah Mada University Press.

Dzun Haryadi Ittiqo, \& Mila Yuni Anderiani. (2017). Optimasi Formula Sediaan Krim Ekstrak Kulit Buah Naga Daging Merah (Hylocereus Polyrhizus). Cendekia, I(I), 6790. 
Engelina NG. (2013). Optimasi Krim Sarang Burung Walet Putih Tipe $M / A$ Dengan Variasi Emulgator Sebagai Pencerah Kulit Menggunakan Simplex Lattice Design. Universitas Tanjung Pura.Pontianak.

Erika Chow, \& Mahalingaiah, S. (2017). Cosmetics use and age at menopause. HHS Public Access, IO6(4), 978-990. https://doi.org/I0.1016/j.fertnstert.2016.0 8.020.Cosmetics

Faizal, A., Razis, A., Ibrahim, M. D., \& Kntayya, S. B. (20I4). Health Benefits Of Moringa oleifera. Asian Pasific Journal Of Cancer Prevention, 2, 857I-8576.

FX Grace, C Darsika, KV Sowmya, K Suganya, S. S. (2015). Preparation and Evaluation of Herbal Peel Off Face Mask. American Journal of Pharm Tech Research, 5, 33-336.

Garg, A., Aggarwal, D., Garg, S., \& Singla, A. K. (2002). Spreading of semisolid formulations. Pharmaceutical Technology, September, 84105.

https://doi.org/I0.5I38/ijdd.2010.0975.0 2I5.020I2

Haldar, R., \& Sharda Kosankar. (2017). Moringa Oliefera: The Miracle Tree. International Journal of Advance Research, Ideas and Innovations in Technology, 3(6), 966-970.

Lestari, U. (2017). Formulasi dan Uji Sifat Fisik Lulur Body Scrub Arang Aktif Dari Cangkang Sawit (Elaeis Guineensis Jacg) Sebagai Detoksifikasi. Jurnal Sains Dan Teknologi Farmasi, I9(Desember), 74-79.

M, V. P., Pakki, E., \& Mirawati. (2016). Formulasi Lulur Krim Yang Mengandung Kombinasi Yoghurt Dan Pati Beras Hitam (Oryza Sativa L.). As-Syifaa, 08(02), 83-9I.

Mishra, A. P., Saklani, S., Milella, L., \& Tiwari, P. (20I4). Formulation and evaluation of herbal antioxidant $\mathrm{N}$ ardostachys jatamansi collected from I ndian $\mathrm{H}$ imalayan face cream of region. Asian Pacific Journal of Tropical Biomedicine, 4(Suppl 2), 2-5. https://doi.org/IO.I2980/APJTB.4.20I4A PJTB-20I4-0223

Mukhlishah, N. R. I., Sugihartini, N., \& Yuwono, T. (2016). Daya Iritasi Dan Sifat Fisik Sediaan Salep Minyak Atsiri Bunga Cengkeh ( Syzigium Aromaticum ) Pada Basis Hidrokarbon Unguentum Volatile Oil of Syzygium Aromaticum. I2(I), 372-376.

Sari Neng Hari. (2015). Pengaruh Penggunaan Lulur Zaitun Terhadap Perawatan Kulit Tubuh. Universitas Negeri Padang.

Triastuti D, K, N. D., Sartika, K. S., A, D., \& D, P.
U. (2018). Formulation of The Body Scrub Cream from Purple Sweet Potato (Ipomoea batatas L.). 5(I), 26-30.

Widya, A., Agustie, D., \& Samsumaharto, R. A. (2013). Uji aktivitas antibakteri ekstrak maserasi daun kelor (. Biomedika, 6(2). 